Geopolítica(s) Revista de estudios sobre espacio y poder ISSN: 2172-3958

https://dx.doi.org/10.5209/geop.69383

\title{
El virus cosmopolita: lecciones de la COVID-19 para la reconfiguración del Estado-Nación y la gobernanza global
}

\author{
Natalia Millán ${ }^{1}$ y Guillermo Santander ${ }^{2}$
}

Recibido: 8 de mayo de 2020 / Aceptado: 10 de mayo de 2020

Resumen. La crisis social, económica y política que se ha desencadenado a partir de la pandemia de COVID-19 esta afectando a todos los ámbitos de las organizaciones humanas. Esta epidemia ha puesto en evidencia la vulnerabilidad multidimensional de las sociedades contemporáneas configuradas bajo la lógica del capitalismo global. En este marco, el artículo analiza, en clave cosmopolita, el impacto de la pandemia desde la dialéctica local/global así como los posibles escenarios de respuesta a esta crisis trasnacional. El artículo concluye en la necesidad de reconfigurar y fortalecer los Estadosnación tanto para que estos ofrezcan protección y servicios públicos a su ciudadanía como para desarrollar una mirada cosmopolita que le permita comprehender y gestionar las amenazas trasnacionales a las que se enfrenta la humanidad.

Palabras clave: pandemia de COVID-19; cosmopolitismo; vulnerabilidad humana; capitalismo; riesgos globales.

\section{[en] The Cosmopolitan Virus: Lessons from COVID-19 for Reconfiguring the Nation-State and Global Governance}

Abstract. The social, economic, and political crisis that has developed due to the COVID-19 pandemic is affecting all areas of human organizations. This epidemic has exposed the multidimensional vulnerability of contemporary societies configured under the logic of global capitalism. Within this framework, the article analyses, with a cosmopolitan approach, the impact of the pandemic from the local/global dialectic as well as the possible response scenarios to this transnational crisis. The article concludes that there is a need to reconfigure and strengthen nation states, not only to offer protection and public services to their citizens, but also to develop a cosmopolitan perspective to understand and manage the transnational threats that humanity faces.

Keywords: COVID-19 pandemic; cosmopolitanism, human vulnerability, capitalism, global risks.

1 Profesora asociada del Departamento de Ciencia Política y de la Administración de la Universidad Complutense de Madrid (UCM).

E-mail:nmillana@ucm.es

2 Profesor asociado del Departamento de Historia, Teorías y Geografía Política de la UCM.

E-mail: gsantand@ucm.es 


\section{[pt] O vírus cosmopolita: lições da COVID-19 para a reconfiguração do Estado-nação e a governança global}

Resumo. A crise social, económica e política desencadeada desde a pandemia da COVID-19 está
afetando todas as esferas das organizações humanas. Essa epidemia expôs a vulnerabilidade multidi-
mensional das sociedades contemporanneas configuradas sob a lógica do capitalismo global. Nesse
contexto, o artigo analisa, em chave cosmopolita, o impacto da pandemia a partir da dialética local /
global, bem como os possíveis cenários de resposta a essa crise transnacional. O artigo conclui sobre
a necessidade de reconfigurar e fortalecer os Estados-nação, para que eles ofereçam proteção e servi-
ços públicos a seus cidadãos e, ao mesmo tempo, desenvolvam uma perspetiva cosmopolita que lhes
permita compreender e gerir as ameaças transnacionais que a humanidade enfrenta. Palavras-chave: pandemia da COVID-19; cosmopolitismo; vulnerabilidade humana; capitalismo; riscos globais.

Sumario. Introducción. 1. La doctrina cosmopolita en los principios del siglo XXI. 2. Vulnerabilidad y capitalismo en el sistema político global. 3. Fragilidad humana en tiempos de pandemia global. 4. El mundo ante su espejo: posibles respuestas y escenarios de futuro. 4.1. La respuesta inercial (o la no respuesta). 4.2. La respuesta de repliegue. 4.3 La respuesta cosmopolita. Conclusiones: la necesidad de avanzar hacia Estados cosmopolitizados. Referencias.

Cómo citar: Millán, N., y Santander, G. (2020). El virus cosmopolita: lecciones de la COVID-19 para la reconfiguración del Estado-Nación y la gobernanza global. Geopolítica(s). Revista de estudios sobre espacio y poder, 11(Especial), 251-263.

\section{Introducción}

La crisis multidimensional generada por la pandemia de COVID-19 ha alcanzado dimensiones globales afectando a una parte significativa de las sociedades humanas. Esta crisis ha demostrado empíricamente que nos encontramos en un momento de emergencia trasnacional que ha puesto en evidencia los procesos de interdependencia propios de la actual etapa globalizadora donde se han generado riesgos planetarios que amenazan la supervivencia de toda la humanidad (Beck, 2005). Es necesario destacar en este análisis que estos fenómenos - con naturaleza de males públicos globales - derivan principalmente del tipo de mundialización capitalista que se ha erigido en el sistema internacional donde se priman las acciones encaminadas a la construcción de un mercado único de capitales y mercancías sobre las políticas orientadas a la protección de las personas y la promoción del desarrollo sostenible. Esta configuración capitalista ha generado una importante reestructuración del poder en el ámbito local/global ampliando los espacios de los actores trasnacionales con intereses privados y debilitando, al tiempo, las fortalezas y capacidades del Estado tanto para regular los sectores económicos como para proteger los derechos de las personas y los servicios públicos.

Los elementos mencionados ponen de manifiesto la necesidad de reconfiguración del Estado nación en dos ámbitos: i) por una parte, se observa la necesidad de fortalecer a estos actores para que tengan capacidades para desarrollar políticas que protejan a la población de las amenazas y riesgos a los que se enfrentan las sociedades, como es el caso actual de la pandemia de COVID-19; ii) por otra parte, es importante reconfigurar la visión y concepción del Estado en clave cosmopolita 
para que este sea capaz de ampliar la mirada para comprehender los desafíos de los procesos trasnacionales así como la necesidad de avanzar hacia una acción cooperativa para gestionar estos mismos procesos.

Bajo este paradigma, el presente artículo pretende analizar, en clave cosmopolita, la pandemia de COVID-19 que ha puesto de manifiesto las diferentes falencias para la seguridad humana que caracterizan a las sociedades contemporáneas. Con este objetivo, después de esta introducción, el segundo epígrafe analiza las potencialidades de la mirada cosmopolita para comprehender el mundo globalizado en que vivimos; el tercero estudia la vulnerabilidad humana que se ha erigido en el marco del capitalismo global; la cuarta sección se dedica a analizar las posibles respuestas y consiguientes escenarios que pueden adoptar los Estados en este contexto; y, por último, el quinto epígrafe cierra con un conjunto de conclusiones derivadas del análisis anterior.

\section{La doctrina cosmopolita en los principios del siglo XXI}

La concepción de que nos encontramos en un mundo único e interdependiente donde existe una sola comunidad ético/política (la humana) que debe proveer protección y derechos a todos sus miembros es un elemento cardinal del desarrollo del pensamiento político y filosófico de nuestras comunidades. De esta forma, el "ideal cosmopolita" que propugna la constitución de sociedades inclusivas, donde las personas son sujetos de derecho independientemente de su pertenencia jurídica a una comunidad particular (Cattafi, 2014) ha estado presente desde los albores de la constitución de las sociedades humanas. Así, las primeras construcciones analíticas que configuran el cosmopolitismo datan del pensamiento griego y han evolucionado a través de la historia hasta lo que se considera cosmopolitismo contemporáneo cuyas concepciones y propuestas se encuentran imbricadas en los cambios estructurales que supone la globalización.

Dos son los elementos constitutivos de la visión cosmopolita: por una parte, la certeza de que nos encontramos en un mundo donde la única frontera real son los límites del planeta, una comunidad universal que no puede ser comprehendida ni gestionada sino se asume su ontología global; por otra, el fundamento de que son las personas las que deben estar en el centro del sistema político (nacional y global) sin sufrir discriminaciones derivadas de cualquier tipo de condición o nacionalidad (Habermas, 1999; Giddens, 2007). Así, a lo largo de la historia el cosmopolitismo ha desarrollado un constructo teórico basado en la justicia universal, la construcción de la paz, la protección de los derechos humanos, el respeto por el valor y la igualdad de la condición humana y la existencia de una comunidad que incorpora la dialéctica global y local (Nussbaum, 2006; Archibugi, 2004).

Cabe destacar que, a pesar de la fuerza normativa del cosmopolitismo, esta visión se ha criticado a lo largo de la historia como un hecho "ideal" sin capacidad para hacer frente a los desafíos reales que supone la práctica política (Meinecke, 1908 [1983]). Por el contrario, ha sido la razón de Estado la base política sobre la que se ha estructurado el mundo contemporáneo. En este marco, el sistema moderno se estructura sobre cuatro condicionantes: i) el mundo se divide en fronteras y límites conformados en Estados que delimitan la soberanía y el territorio; ii) la "razón de Estado" y los llamados intereses nacionales son los elementos fundamen- 
tales sobre lo que se debe estructurar la política pública; iii) el acceso a derechos y protección depende de la pertenencia a un Estado; y iv) la relación entre Estados se dirime en la competencia y la "lucha" por los recursos y la seguridad. Esta es la base política, económica y social sobre las que se ha configurado el mundo actual, bases ontológicas que, como es posible inferir, son esencialmente contrarias a los postulados básicos del cosmopolitismo.

Ahora bien, a partir de las décadas de 1970/1980 se han profundizado y expandido los procesos de transnacionalización e interdependencia fruto de la actual etapa globalizadora lo que ha reconfigurado las dinámicas de las organizaciones humanas, reestructurando las relaciones entre actores, países y sociedades. Este proceso que supone por una parte una expansión del capitalismo y por otro un aumento profundo de las interdependencias e interconexiones entre países y personas nos ha colocado en un mundo de "comunidades de destinos solapadas" (Held, 2005, p.1). En este contexto, es justamente la perspectiva hegemónica considerada "realista" basada en la razón de Estado, la competencia y la lucha por la supervivencia la que no parece ofrecer un marco para la seguridad humana. De ahí, que los autores cosmopolitas contemporáneos afirmen que la única forma de comprehender y gestionar las oportunidades y amenazas para la seguridad humana es la ontología cosmopolita (Nussbaum, 2006; Delanty, 2000).

\section{Vulnerabilidad y capitalismo en el sistema político global}

Como se señala desde la literatura cosmopolita —aunque no solo desde ella—, nos encontramos en un sistema de interdependencias complejas, multiescalares y multidimensionales que han configurado una sociedad global que comparte desafíos y vulnerabilidades comunes. Cabe destacar que el cosmopolitismo planteado en este artículo no aboga por la disolución de las identidades locales o Estados nacionales sino por la redefinición de un Estado "cosmopolitizado" que asuma la visión normativa de la inclusión y el reconocimiento del otro y que sea capaz de diseñar y proponer respuestas colectivas globales y realistas para gestionar los desafíos a la seguridad humana. De esta manera, se vincula el reconocimiento de la entidad estatal con una teoría política y una ontología imbricada en lo nacional/trasnacional.

Ahora bien, el hecho de que vivamos en una sociedad del riego global donde las personas se encuentran hermanadas por una vulnerabilidad común (Beck, 2006) encuentra sus raíces explicativas en las características capitalistas de este proceso más que en la dinámica globalizadora de interdependencia e integración. La vulnerabilidad, la fragilidad y la interdependencia es una condición propia de la naturaleza humana y es la gestión de esta vulnerabilidad la que ha llevado a las comunidades a organizar la vida en común a través de una res pública. A pesar del desarrollo moderno del concepto de individualidad y competencia en que se basa el sistema económico dominante, las personas se encuentran encarnadas en cuerpos frágiles que necesitan para poder sobrevivir tanto de los cuidados de otros seres humanos como de los elementos biofísicos y materiales que se encuentra en el planeta Tierra (Herrero, 2018). Así, la evidencia científica ha demostrado que la configuración y la evolución de las sociedades humanas necesitan de la cooperación y el apoyo mutuo para expandirse y sobrevivir (Nowak, 2006). 
En este sentido, la doctrina cosmopolita se encuentra estrechamente vinculada con la teoría del desarrollo humano (Sen, 1999), el concepto de la seguridad humana (Naciones Unidas, 1994) y las perspectivas posdesarrollistas vinculadas a la idea de "colocar la vida en el centro" del sistema social (Herrero, 2018; Pérez, 2014). Aunque con matices, estas visiones establecen que son los individuos los que deben estar en el centro del sistema político y que la sociedad debe configurar sistemas económicos y sociales compatibles y en armonía con todas las formas de vida del planeta Tierra. En este marco, el Estado debiera tener la capacidad para salvaguardar a los individuos de las privaciones al tiempo que desarrollar políticas públicas que promuevan los derechos humanos y la protección de la naturaleza. De esta forma, estos planteamientos proponen el fortalecimiento de Estados democráticos, redistributivos y garantes de derechos que sean capaces de gestionar los riesgos multiescalares que están emergiendo en las sociedades transnacionalizadas.

En contraposición, el proceso de globalización capitalista se ha erigido como un proyecto de construcción de un mercado único global, sin límites ni intervenciones por parte de los Estados que van perdiendo capacidad para gestionar sus asuntos públicos. Así, desde la década de 1970, se han intensificación a lo largo del globo los movimientos de mercancías, capitales, personas e informaciones que cuestionan las fronteras nacionales westfalianas creando una nueva geografía del poder que desdibuja las fronteras territoriales y el concepto tradicional de soberanía (Dilla y Hansen, 2019). En efecto, la sociedad internacional ya no es sólo (o principalmente) una sociedad de Estados, sino también un sistema de redes trasnacionales que forman parte constitutiva de las estructuras de poder donde es posible distinguir entre una diversidad de actores trasnacionales que - con distinto alcance y naturaleza - han logrado apropiarse de importantes cuotas de capacidades políticas, económicas, financieras y mediáticas. Dentro de este grupo, destacan las empresas trasnacionales, los bancos y las corporaciones que son actores fundamentales de la economía global que compiten en un mercado que tiende a ser único, internacionalizando sus estrategias, políticas y sistemas de producción. Estos actores poseen un poder cada vez más importante asociado al sistema capitalista $-\mathrm{y}$ a la desregulación económica y los avances tecnológicos - y llevan a cabo importantes injerencias en los gobiernos nacionales, lo que ha supuesto una pérdida de legitimidad democrática para una parte importante de las sociedades occidentales.

En definitiva, es la dinámica capitalista globalizada la que ha desplazado las relaciones de poder, debilitando al Estado para que ejerza sus funciones de protección y cuidado de la sociedad, aumentando la capacidad del capital para influir en los procesos de toma de decisiones públicas en favor de sus intereses privados y generando en definitiva una "desposesión de lo común" donde las élites se apropian y mercantilizan los espacios comunes de convivencia colectiva (Harvey, 2014). Como se verá en el siguiente epígrafe se trata de un marco extremadamente precario, restringido y limitado para gestionar los males públicos globales a los que se enfrenta la humanidad.

\section{Fragilidad humana en tiempos de pandemia global}

Al momento de redactar este artículo (principios de mayo de 2020), la sociedad humana se encuentre inmersa en una pandemia global de COVID-19 ocasionada 
por el SARS-CoV-2. Este virus se identificó por primera vez en diciembre de 2019, en la provincia de Wuhan, China, y en el lapso de tres meses se ha extendido a más de 185 países, con 3,7 millones de casos confirmados y aproximadamente 263.000 personas fallecidas en todo el mundo ${ }^{3}$. Al ser extremadamente contagioso, el virus se ha diseminado por todo el planeta, aunque parece haber afectado con mayor virulencia a las zonas del mundo más expuestas a la internacionalización y al tráfico global de mercancías y personas, es decir a Europa y Estados Unidos. Como consecuencia de la facilidad de contagio del virus y la rápida expansión de la pandemia, actualmente se calcula que más de 3.000 millones de personas se encuentran confinadas en sus domicilios y, debido a la paralización de la industria, el transporte y los servicios, el mundo se encuentra inmerso en la mayor crisis económica y social desde la Segunda Guerra Mundial.

La experiencia que la humanidad está teniendo en la gestión de la pandemia, con un elevado número de muertes y contagiados, está afectando a todas las dimensiones de las organizaciones humanas ocasionando cierres de fronteras e implantación de Estados de Alarma que suspenden temporalmente algunos derechos fundamentales. Las diversas crisis sanitarias y sociales suscitadas desde la aparición del virus han puesto de manifiesto la vulnerabilidad de los Estados para proteger la vida humana y las contradicciones de sociedades que han colocado en el centro el crecimiento económico por encima de otras consideraciones relacionadas con el desarrollo humano y sostenible. De esta manera, los sistemas contemporáneos han priorizado la lógica del beneficio sobre la lógica del cuidado y el sostenimiento de la vida (Novo, 2020). En este sentido, la crisis de la COVID-19 está evidenciando las enormes fragilidades del paradigma neoliberal al tiempo que promueve la reaparición del Estado como protector de la vida de las comunidades; en efecto, en la mayor parte de los países, es el Estado el que está asumiendo los principales instrumentos de acción a través del fortalecimiento de los servicios sanitarios, la política de ayuda a los dependientes, la protección de los trabajadores que se encuentran sin actividad laboral, la asistencia a las familias vulnerables, los seguros de desempleo, y una amplia batería de políticas públicas que pretenden asistir a la población de los riesgos derivados de la pandemia. Y es que la realidad ha demostrado que el mercado no posee herramientas para promover los bienes públicos y que en casos de emergencia - como es la propia pandemia, un conflicto bélico o un desastre natural - es la política pública entendida como gestión del bien común, la única capaz de proteger y promover la seguridad humana.

Se trata, además, de un fenómeno de clara naturaleza cosmopolita, dado que el virus está impactando - aunque de manera divergente - a los gobiernos y sociedades de la mayor parte de la humanidad. Como se ha explicado, las amenazas globales a los que se enfrenta la humanidad derivan de los procesos más avanzados del desarrollo tecnológico que en nuestras sociedades tienen que ver principalmente con la degradación del planeta, las sustancias radioactivas o la capacidad nuclear extermino total (Beck, 2006). De esta forma, se ha creado un sistema económico capitalista trasnacional que asume que el crecimiento económico es el único indicador de bienestar de las sociedades generando una degradación tan amplia de la

Información obtenida de la página web del ISGLOBAL https://www.isglobal.org/coronavirusa a fecha de 28 de abril de 2020 . 
naturaleza que se ha puesto en riesgo la propia supervivencia de la especie humana ${ }^{4}$ (Steffen et al., 2018; Ripple et al., 2020). En este sentido, existen diversos estudios que relacionan la destrucción de la naturaleza con la aparición de enfermedades infecciosas transmisibles al ser humano como es la propia pandemia de COVID-19 (WWF, 2020; Jhonson et al., 2020).

En suma, es posible aseverar que la crisis de COVID-19 abre la puerta a un diagnóstico relativamente compartido acerca de tres elementos fundamentales: i) la importancia de poner la vida y la vulnerabilidad en el centro de la gestión pública; ii) la necesidad de reforzar el papel del Estado como garante de la supervivencia humana; y iii) la importancia de asumir que estamos en una sociedad del riesgo global y que las amenazas derivadas del capitalismo globalizado no conocen límites ni fronteras.

\section{El mundo ante su espejo: posibles respuestas y escenarios de futuro}

Los grados de incertidumbre que acompañan a la crisis actual provocada por la COVID-19 hacen imposible vaticinar la evolución futura que experimentarán un amplio número de cuestiones que afectan a ámbitos tan diversos como la salud, las relaciones sociales, la sostenibilidad medioambiental, la seguridad, el trabajo o la economía. No obstante, es posible identificar tres grandes matrices de respuesta por las que los gobiernos deberán optar y los diversos escenarios a los que cada una de ellas podría conducirnos. A presentar estas posibles respuestas (inercia, repliegue o cosmopolitismo) y a destacar los principales elementos que caracterizarían a cada uno de esos eventuales escenarios se dedican los siguientes apartados.

\subsection{La respuesta inercial (o la no respuesta)}

Una primera opción de respuesta es aquella en la que no se experimentarían grandes cambios respecto a la matriz actualmente existente y que, por tanto, mantendría sustancialmente la lógica con la que los gobiernos han venido operando en estas últimas décadas. La acción política seguiría descansando así, de manera prácticamente exclusiva, en la concepción clásica de soberanía nacional y en marcos de alcance estatal, a pesar del notable y creciente protagonismo adquirido por los desafíos e interdependencias de carácter global. Se seguiría intentando responder a los desafíos de naturaleza global fundamentalmente a través de la mera agregación de respuestas bilaterales protagonizadas por los Estados. Unas respuestas bilaterales que, no obstante, se seguirían acompañando de experiencias puntuales y ad hoc de coordinación de los Estados bajo diversos, y cada vez más heterogéneos, formatos (como el G-20) y acudiendo tan solo de forma subsidiaria y complementaria a los organismos multilaterales.

Varios son los rasgos que caracterizarían al escenario al que daría lugar este tipo de respuesta inercial. En primer lugar, cabe suponer que persistiría una importante brecha de gobernanza: la producida entre la naturaleza global de los fenómenos a

4 Los textos citados corresponden a dos importantes artículos avalados por más de 15.000 científicos de 184 países donde se advierte de la gravedad de la crisis ambiental y de la necesidad urgente de tomar medidas antes que el tiempo se "agote". 
los que se quiere atender y el carácter estatal de las respuestas articuladas (Beck, 2005; Held, 2005). Así, las respuestas y soluciones planteadas serían, en el mejor de los casos, parciales e imperfectas, como nos está demostrando la COVID-19 y como es de suponer que nos recordarían otros desafíos futuros similares. Lógicamente, existirán acciones políticas gubernamentales que resultarán más o menos exitosas para dar respuesta a estos desafíos, en función del perfil y enfoque que cada una adopte, pero parece poco probable que los Estados pudieran llegar a alcanzar a través de esta óptica unos umbrales mínimos de estabilidad, justicia social y seguridad humana. Más bien al contrario la mera articulación de respuestas bilaterales para abordar desafíos de naturaleza global parece abocar, como estamos viendo en la actualidad, a un progresivo incremento de la inestabilidad y de la vulnerabilidad de las sociedades y personas que conforman dichos Estados. Nos encontraríamos con mucha probabilidad en un escenario de crisis cíclicas —en ámbitos como el sanitario, el climático, el social o el económico- que golpearían, además, a un entorno internacional caracterizado por un sistema multilateral débil, que no gozaría de las capacidades y del respaldo político necesario para desempeñar un rol más relevante en la gestión de estos fenómenos.

En segundo lugar, no solo sería difícil conformar respuestas eficaces y acordes a la naturaleza de los retos que se quieren abordar, sino que se generarían otros efectos políticos colaterales indeseados. Por ejemplo, en un contexto tan fragmentado, caracterizado fundamentalmente por la suma de respuestas bilaterales de los Estados, será difícil identificar y atribuir responsabilidades y, lo que es más importante, extraer lecciones y aprendizajes para prevenir y gestionar mejor las crisis y los retos futuros. Será difícil evaluar la pertinencia y los resultados de cualquier acción de gobierno si se actúa de manera aislada en un contexto interdependiente en el que influyen muchos factores externos y ajenos a esas decisiones que se toman bilateralmente.

Por último, al concentrar la respuesta en la articulación de políticas desde una lógica bilateral estatal, las decisiones adoptadas en este escenario seguirían viéndose más expuestas y sometidas a los ciclos electorales de cada país. Un elemento que en ocasiones puede estimular un cierto cortoplacismo en la toma de decisiones políticas, desplazando la adopción de medidas más estratégicas y eficaces cuyo impacto es más observable en el medio y largo plazo y que, por tanto, carecen de un rédito electoral inmediato.

\subsection{La respuesta de repliegue}

Una segunda opción de respuesta sería aquella que fomentase un refuerzo y repliegue hacia el Estado-nación. A diferencia de la opción anterior, en este caso no se trataría de que persistan unas lógicas e inercias adquiridas en la práctica política que no permiten superar la brecha de gobernanza señalada, sino que se basaría en una apuesta deliberada por reforzar la soberanía estatal clásica, blindándola como principio ordenador absoluto de la sociedad internacional. Una apuesta que significaría, por tanto, la oposición a cualquier ejercicio de atribución o transferencia de competencias a instituciones internacionales o supraestatales. Se trataría de una respuesta defensiva que fundamentalmente se orientaría a contener los efectos de la globalización a partir de una estrategia cercana a la "táctica del avestruz": el Estado se cerraría hacia adentro, casi esperando en cierto modo a que la globalización 
desapareciese, como si fuera un diluvio o un fenómeno pasajero frente al que simplemente hay que aguantar y resistir.

Esta respuesta de repliegue, promovida en la actualidad por distintos grupos de la ultraderecha política, podría dar lugar a un escenario del que cabe anticipar algunos rasgos. En primer lugar, se profundizaría la incapacidad de los Estados para dar respuestas eficaces a demandas y desafíos que trascienden las fronteras estatales y que tienen una naturaleza trasnacional, incrementando la brecha de gobernanza descrita. Incluso aquellos Estados que pudieran considerarse más fuertes y exitosos en este escenario serían incapaces de garantizar cuestiones básicas como la salud de su población - piénsese en la actual crisis de la COVID-19 o en posibles pandemias futuras similares-, la estabilidad financiera de su economía, la paz o la preservación del entorno natural que hace posible la vida humana.

En segundo lugar, esta respuesta produciría un incremento del populismo y una exaltación de las identidades nacionales, reforzando una lógica de muros y fronteras y activando dinámicas de exclusión frente a "lo de fuera" en ámbitos muy diversos, pero particularmente frente las personas más vulnerables. Además, como la historia trágicamente se ha encargado de demostrar, se trata de un tipo de conductas que tienden a alentar la conflictividad entre Estados, activando dinámicas competitivas que, muy probablemente, caracterizarían a este escenario. Se abriría así un periodo de tensión e inestabilidad en un sistema internacional que se vería convertido en un mero espacio de disputa, en el que confluirían un amplio número de Estados compitiendo entre sí y conformando alianzas transitorias de todo tipo para alcanzar sus intereses particulares.

En suma, asistiríamos a un sistema internacional caracterizado por la desconfianza, la opacidad y la ausencia de mecanismos que garanticen una cierta capacidad de diálogo a escala internacional. Un escenario ya no de debilitamiento del sistema multilateral, sino de abierta confrontación hacia él, lo que prácticamente anularía la existencia de vías para canalizar la acción colectiva internacional y para dotarnos de acuerdos y normas comunes a escala global. Un contexto en el que las cuestiones clave que requieren una mirada trasnacional, como la mitigación del cambio climático, la movilidad humana, la protección a las personas refugiadas o el control de pandemias —o cualquier otra con naturaleza de Bien Público Internacional-quedarían completamente relegadas en las agendas políticas.

\subsection{La respuesta cosmopolita}

Una tercera opción de respuesta es aquella que tratase de afrontar y conducir la globalización, gestionando las interdependencias que genera. Esta respuesta asumiría que la globalización es una realidad comunicacional irreversible -en cuanto que conecta a todas las personas y sociedades del planeta- y que sus efectos dependerán no tanto de la existencia de dicha interrelación, sino del modelo económico y social bajo el que opere. Se trataría en este caso de articular respuestas políticas orientadas a la construcción de gobernanza global, a partir de la progresiva configuración de una arquitectura institucional internacional que permitiese gestionar problemas de alcance trasnacional, tales como la actual crisis generada por la COVID-19. Una respuesta en la que el Estado tendría también un rol central e ineludible pero en la que, lejos de replegarse y alentar dinámicas excluyentes con otros Estados, actuaría como una entidad catalizadora de la visión y la acción cos- 
mopolitas. Por un lado, sabiéndose interdependiente y, por tanto, con una actitud proactiva en la conformación de espacios de concertación multilateral con otros Estados; y, por otro lado, atendiendo a las demandas y los derechos de su ciudadanía, pero de manera compatible y coherente con la simultánea generación de marcos internacionales que promoviesen y garantizasen los derechos de todas las personas más allá de su lugar de nacimiento. A la vez se trata de una opción que pondría tanto énfasis en la necesidad señalada de disponer de instituciones globales y supraestatales, como en acercar siempre lo más posible la toma de decisiones a la ciudadanía, a través de un sistema multinivel (local-estatal-regional-global). Regiría así un principio de subsidiariedad por el que los problemas debieran ser siempre preferentemente tratados desde el nivel más pequeño que la naturaleza y dimensión del desafío permita (Held, 2005; Archibugi, 2004).

El predominio de este tipo de respuesta daría lugar a un escenario en el que cabría anticipar varios rasgos. En primer lugar, se asistiría a una flexibilización y redefinición de la soberanía estatal clásica, en el sentido de que los Estados tendrían que ir asumiendo la necesidad de compartir o ceder soberanía en algunos ámbitos específicos para poder implementar políticas y respuestas eficaces. Un elemento que llevaría aparejada la necesidad de ir dotándose de un sistema multilateral más robusto, eficaz y democrático, que fuera capaz de vehicular la acción colectiva internacional.

En segundo lugar, esta respuesta podría dar lugar a un escenario de redemocratización en un doble sentido. Por un lado, a escala internacional, cerrando la brecha de gobernanza antes señalada. En la medida en que en la actualidad se sigue tratando de dar respuestas de tipo estatal a fenómenos que son globales, se puede observar la existencia de zonas sin cobertura política. Esto da lugar a espacios de desgobierno - como sucede con la crisis de las personas refugiadas o con el cambio climático - o gobernados por actores privados — como sucede particularmente en el ámbito financiero o laboral- (Strange, 2001; Sanahuja, 2008). La construcción de gobernanza global permitiría reducir esas zonas a las que no está llegando la acción política y que generan inestabilidad y efectos nocivos para todas las sociedades y, particularmente, para las personas que se encuentran en situación de mayor vulnerabilidad. Por otro lado, también podría darse una redemocratización a escala intraestatal, reduciéndose aquellas situaciones en las que se produce una usurpación de la voluntad democrática - expresada por la ciudadanía en las urnas - cuando entidades sin ninguna legitimidad democrática, que escapan de cualquier participación y el control, imponen sus decisiones e intereses a los gobiernos nacionales.

En tercer lugar, por el marco ético y normativo en el que descansa, se trataría de un escenario que otorgaría mayor relevancia y centralidad a la promoción y respeto de los derechos humanos, tratando de garantizar la dignidad a todas las personas más allá del Estado al que se adscriba su ciudadanía o de cualquier otra consideración. Esto daría lugar a un sistema internacional caracterizado no solo por una mayor justicia social, sino también más cohesionado, seguro y estable. Al tiempo, obligaría a revisar los modelos de desarrollo vigentes, transitando hacia fórmulas que situasen los cuidados, tanto de las personas como del planeta, en el centro. Un ejemplo en esta dirección es la denominada Agenda 2030 de Desarrollo Sostenible, un conjunto de objetivos definidos multilateralmente que persigue la conformación de sociedades y modelos de desarrollo que hagan compatible la prosperidad eco- 
nómica con la inclusión social y la sostenibilidad medioambiental (Naciones Unidas, 2015).

\section{Conclusiones: la necesidad de avanzar hacia Estados cosmopolitizados}

El fuerte impacto sanitario, social y económico que la pandemia provocada por la COVID-19 ha generado a escala internacional ha sido una costosa forma de aportar evidencia empírica a lo que desde algunos ámbitos se venía advirtiendo desde hace tiempo: que estamos en un mundo globalizado e interdependiente en el que las sociedades están expuestas a riesgos y desafíos cuyo tratamiento eficaz requerirá, de manera ineludible, la puesta en marcha de respuestas de carácter trasnacional que pongan la vida en el centro. Unas interdependencias que, bajo el paraguas del capitalismo global, conducen necesariamente a una agudización de las incertidumbres de todo tipo, incrementando la inestabilidad y aumentando la vulnerabilidad de las sociedades y personas.

Ante este contexto que la COVID-19 se ha encargado de recordarnos de forma particularmente clara y dolorosa, que existen diversos caminos a tomar en los próximos años cuya elección condicionará de modo muy distinto nuestros modos de vida y de convivencia en las próximas décadas. Como es lógico, los escenarios expuestos en el apartado anterior constituyen tres grandes opciones de respuesta que no se expresarán en la realidad de forma tan nítida y segmentada como se han presentado aquí, sino que probablemente se constituirán en tres visiones en permanente disputa y tensión, que necesariamente convivirán y aparecerán entremezcladas en los próximos años. Lo relevante será saber si alguna de ellas logrará alcanzar una correlación de fuerzas suficientemente favorable que le permita ganar peso y convertirse en hegemónica sobre las otras.

Teniendo en cuenta el proceso de globalización en curso y la naturaleza de los grandes desafíos a los que nos enfrentamos, parece claro que sería preferible avanzar hacia el tercero de los escenarios. Evidentemente no es un camino sencillo, al que desde muchos ámbitos se le acusa de idealista, poco pragmático y alejado de la Realpolitik. No obstante, por un lado, y como nos recuerda Beck, menos realista aún que esta opción parece la de seguir pensando que desde la lógica estatal clásica se vaya a poder dar respuestas al tipo de desafíos que tenemos en la actualidad. Se trataría, por tanto, de transitar hacia lo que se denomina un nuevo realismo cosmopolita (Beck, 2005). Por otro lado, no hay que olvidar que también la aparición del Estado, al que hoy concebimos como una entidad inmanente e inmutable, ha respondido a un proceso de construcción histórica, que data de no más de cinco siglos de existencia. Visto en perspectiva histórica, podríamos estar inmersos en un proceso similar de paulatina construcción de estructuras políticas supranacionales, complementarias y no sustitutivas del Estado, que nos vayan a permitir afrontar mejor los retos a los que nos tendremos que enfrentar en el futuro.

En cualquier caso, por la complejidad e incertidumbres que la transición hacia ese escenario implica, deberá entenderse como un proceso abierto al aprendizaje continuo, donde será necesario asumir algunos grados de experimentación e innovación a la hora de conformar nuevas formas de gobernanza y de participación democrática (Innerarity, 2020). Parece lógico pensar, además, que el tránsito hacia ese tercer escenario tendrá que convivir bastante tiempo con lógicas muy arraiga- 
das en el primero de esos escenarios, particularmente con lo que se refiere a la soberanía estatal clásica. En ese sentido es claro que tiene que seguir siendo clave el papel de los Estados, que ineludiblemente seguirán siendo el marco político fundamental de referencia. Pero podrían abrirse espacios para una progresiva cosmopolitización de estos Estados, de tal forma que se preserve - incluso refuerce - su protagonismo a la vez que se transita hacia un escenario de mejor gobernanza global. Frente a falsos dilemas que en ocasiones contraponen la construcción de gobernanza global y de un sistema multilateral sólido, por un lado, y la existencia de Estados fuertes, por otro, el contexto actual demuestra que es necesario $-\mathrm{y}$ posible - compaginar ambos elementos. Se requerirán Estados fuertes, que sean capaces de ofrecer la protección y los servicios públicos que el contexto de crisis generada por la COVID-19 va a demandar, pero que a la vez tengan una visión abierta hacia afuera, asumiendo sus responsabilidades como parte del sistema internacional, promoviendo una mejor gobernanza global y, en definitiva, velando por garantizar los derechos de todas las personas más allá de su lugar de nacimiento.

\section{Referencias}

Archibugi, D. (2004). "La democracia cosmopolita". Papeles de Cuestiones Internacionales, (87), 43-59.

Beck, U. (2005). La mirada cosmopolita o la guerra es la paz. Barcelona: Paidós.

Beck, U. (2006). La sociedad del riesgo global. Madrid: Siglo XXI Editores.

Cattafi, C. (2014). Las acepciones del término cosmopolitismo: una aportación a la taxonomía de Kleingeld. CONfines, 10(19), 9-33.

Delanty, G. (2000). Citizenship in a Global Age. Buckingham: Open University Press.

Dilla, A., y Hansen Figueroa, K. (2019). El gobierno de las territorialidades transfronterizas internacionales: la experiencia latinoamericana. Geopolítica(s). Revista de estudios sobre espacio y poder, 10 (2), 259-279.

Giddens, A. (2007). Las nuevas reglas del método sociológico. Buenos Aires: Amorrortu Editores.

Habermas, J. (1999). La inclusión del otro. Estudios de Teoría Política. Barcelona: Paidós.

Harvey, D. (2014). Diecisiete contradicciones y el fin del capitalismo. Madrid: Traficantes de sueños.

Held, D. (2005). Un pacto Global. Madrid: Editorial Taurus.

Herrero, Y. (2018). Sujetos arraigados en la tierra y los cuerpos. Hacia una antropología que reconozca los límites y la vulnerabilidad. Cuadernos de trabajo 3. Ciclo seis contradicciones $y$ el fin del presente. Recuperado de https://www.museoreinasofia.es/sites/default/files/actividades/programas/cuaderno_de_t rabajo_3_taylor-herrero.pdf

Innerarity, D. (2020). Una teoría de la democracia compleja. Gobernar en el siglo XXI. Barcelona: Galaxia Gutenberg.

Johnson, K., Hitchens P., Pandit, P., Rushmore, J., Evans, T.S., Young, C., y Doyle, M. (2020). Global shifts in mammalian population trends reveal key predictors of virus spillover risk. Proceedings of the Royal Society Publishing. B. 28720192736

Meinecke, F. (1908 [1983]). La idea de la Razón de Estado en la Edad Moderna. Madrid: Centro de Estudios Constitucionales. 
Naciones Unidas (1994). Informe sobre Desarrollo Humano 1994. Nueva York: Naciones Unidas.

Naciones Unidas (2015). Transformar nuestro mundo: la Agenda 2030 para el Desarrollo Sostenible. Nueva York: Naciones Unidas.

Novo, M. (2020). Reflexiones de la nueva era. El Diario de la Educación, 28 de abril. Recuperado de https:/eldiariodelaeducacion.com/2020/04/28/la-logica-del-beneficioinmediato-ha-destruido-la-logica-de-la-vida/

Nowak, A. (2006). Five rules for the evolution of cooperation. Science, (314), 1560-1563.

Nussbaum, M. (2006). Frontiers of Justice: Disability, Nationality, Species Membership. Cambridge: Belknap Press

Pérez, A. (2014). Subversión feminista de la economía. Aportes para un debate sobre el conflicto capital/vida. Madrid: Traficantes de sueños.

Ripple, W., Wolf, C., Newsome, T., Barnard, P., y Moomaw, W. (2020). World Scientists' Warning of a Climate Emergency. BioScience, 70(1). Recuperado de https://academic.oup.com/bioscience/article/70/1/8/5610806

Sanahuja, J. (2008). ¿Un mundo unipolar, multipolar o apolar? El poder estructural y las transformaciones de la sociedad internacional contemporánea. En VVAA, Cursos de Derecho Internacional de Vitoria-Gasteiz 2007 (pp.297 -383). Vitoria: Servicio Editorial Universidad del País Vasco.

Sen, A. (1999). Desarrollo y Libertad. Barcelona: Planeta.

Steffen, W., Rockström, J., Orcid, V., Richardson, P., Timothy, M., Lenton, M., y Schellnhuber, J. (2018). Trajectories of the Earth System in the Anthropocene. PNAS, $115(33), 8252-8259$.

Strange, S. (2001). La retirada del Estado. La difusión del poder en la economía mundial. Barcelona: Icaria.

WWF (2020). Pérdida de naturaleza y pandemias. Un planeta sano por la salud de la humanidad. Madrid: WWF 